\title{
Organisation Team Sport Interventions to Overcome Diversity Constraints in the Workplace
}

\author{
Yvonne Joubert, University of South Africa, South Africa \\ Hannes de Beer, University of Pretoria, South Africa
}

\begin{abstract}
Particular organisations which implement formal organisational team sport participation, do not know whether the specific sport intervention contributes to the diversity management objectives of the organisations. A qualitative study was done to determine whether organisation team sport interventions have an impact on the participating employee's relationships, trust and respect towards each other despite their differences. The diversity constraints relevant in this study are race, ethnicity, generation gaps, gender, sexual orientation, socio-economic status, age, physical abilities, religious beliefs, political beliefs, parental status, education and income. The study was conducted among 26 employees employed at two financial organisations in South Africa and participating in organisation team sport. The data was collected by means of focus group interviews and individual interviews where open-ended questions and probing questions to participants were asked. Data analysis was used to make sense of, formulate and arrange the data so that it can be presented in a clear and logical account. Lastly, a conclusion of this study and discussion of the limitations and recommendations for organisations in terms of the implementation of organisation team sport interventions to overcome diversity barriers in an organisation, as well as further research was made.
\end{abstract}

Keywords: Diversity, Diversity Management, Organisation Team Sport, Communication, Relationship, Trust, Goals, Respect, Cohesion, Commitment

\section{Introduction}

$\mathrm{W}$

ORLDWIDE ECONOMIC RECESSIONS, such as that experienced in 2008-2009, place exceptional strain on organisations in terms of survival and sustained performance.

About 67000 jobs were lost in the formal sector in South Africa between April and June 2009. A survey by Stats SA indicates that the workforce declined by $0,8 \%$ in the second quarter, reducing the total number of people employed to an estimated 8,26 million. Thousands of jobs have been lost, in particular in the mining, manufacturing and construction sectors (E-News Late Edition 2009). As a result, it becomes increasingly important for organisations to manage the declining workforce more effectively.

In organisations with extremely diverse workforces the challenge is even greater if diversity is not consciously and effectively managed.

The present article explores whether participation in a formal organisation team sports programme influences the perceptions of a group of participants regarding a number of diversity constraints. 


\section{Literature Study}

\section{Diversity Management}

To manage diversity effectively in an organisation, it is necessary to meet various requirements. Some of these are explored in more detail below.

\section{Shared Organisational Goals}

For a diverse team to succeed, it must have shared, achievable goals that unite team members; these goals must have discussed and agreed on (Solomon 1998:2). One of the main solutions to diversity constraints in an organisation entails ensuring that shared or common, achievable goals are set.

\section{Personal Commitment}

For diversity management to succeed in the organisation, every employee needs to commit to cooperating with employees who are different (Bassett-Jones 2005:169). If there is no personal commitment, diversity may create conflict, misunderstandings and suspicion in the workplace, which may result in low morale, absenteeism and loss of production.

\section{Interpersonal and Intergroup Trust and Respect}

Trust is a vital component of diversity management. Employees will not give of their best during diversity management initiatives unless they believe that they can trust one another. Misunderstandings, conflict and suspicion among employees are often caused by distrust, which undermines diversity management; it weakens employee morale, further affecting the integrity of employees participating in a team working towards a common goal (Nieman \& Bennett 2002:334).

\section{Effective Communication}

In the case of a diverse workforce, effective communication is important. It is not always easy for employees from different cultural groups to communicate their views effectively, even when there are no language barriers. It must be ensured through diversity management that employees from different groups are able to communicate their views effectively so as to avoid misunderstandings and miscommunication (Nieman \& Bennett 2002:332).

\section{Knowledge about Other Groups}

Staff members need to realise and understand that other staff members are different and unique. They can use this insight to create an environment that offers greater scope for personal growth and productivity (Solomon 1998:2). Ignoring or avoiding the existence of cultural influences does not build a sense of either belonging or esteem, and will invariably create conflict (Nieman \& Bennett 2002:338). 


\section{Organisational Team Sport}

The contribution of sport to effective diversity management in an organisation is discussed in more detail below.

\section{Opportunities to Share Goals}

Organisational sports teams have a specific shared main goal, namely winning. Sometimes long-term goals can be broken down into a series of short-term goals. The achievement of delimited and realistic goals can lead to the setting of further objectives that will enable a team to achieve its ultimate goals effectively (Cashmore 2003:126).

\section{Individual Commitment}

Participation in organisational team sport improves individual commitment because it requires the participant to remain focused on specific goals. A certain level of commitment is required; this may take the form of improving certain skills, being present for training, or refraining from certain other activities (Cashmore 2003:66).

\section{Mutual Trust and Respect}

When a sports team works together towards common goals and these are achieved, the stereotyping and prejudices that participants might have had about their team members from other groups are reduced. Simultaneously, mutual trust develops, because the participants perform according to the expectations their team members have of them (Kortex 2006:1).

Participation in organisational team sport improves mutual respect among employees because participants learn to value each participant's contribution to the success achieved. When each participant's contribution is highly regarded, the outcome is mutual respect. Team sport teaches employees that each participant has his or her own role and that to fulfil the role assigned to them, team members need to respect one another (Downs 2009:1).

\section{Open Communication}

Participation in organisational team sport improves communication among employees, because in order for the team to perform, people have to communicate effectively. Effective communication binds people together, despite differences in their culture, economic status, religious beliefs or background. Effective communication also breaks down barriers, which is important when integrating different cultures and norms (Carrigg 2007:1).

\section{Interpersonal Knowledge}

Participation in organisational team sport enhances employees' knowledge of others because they share the same physical space and transfer information. Participation in sport can strengthen friendships and achieve harmony between diverse groups (Muleskinner 2003:1). Lapchick (2005:2) is the leader in racial equality and is internationally recognised as an expert on sports issues and participation. He is of the opinion that organisation team sport can be 
used as an effective tool to improve knowledge of other employees and effect positive social change.

\section{The Influence of Sport Participation on Work Success}

In a study conducted by Standard Chartered Bank (Sawer 2007), it was found that employees who participate in a team sport, such as soccer or netball, are more successful than nonparticipants in their work. In this study, it was found that more employees who participate in organisation team sport work in fast-growing organisations and this may indicate that they have a positive influence on this rapid growth. It could also be that employees participating in sport are generally more motivated to improve organisational productivity and performance.

Sawer's (2007:33) research indicates that there is a significant positive correlation between team sport participation and benefits for the organisation.

Additional findings of the study were the following:

- A total of $48 \%$ of the participants agreed that the relationship between the normal workforce and management has improved.

- Of the participants, $80 \%$ reported that they learnt to know different employees from different departments.

\section{The Benefits of Participation in Netball for Employees}

In a study by Hewett (2001:34) at the University of New South Wales (Sports Medicine Department) (2001), it was shown that employees, who keep on playing netball during adulthood, learn how to

- $\quad$ set goals because they are used to setting goals during a netball game

- become more effective leaders - during a netball game, the participants know how to lead others to achieve the goals that are set

- work in a group because a netball team can only succeed if all the participants are able to work together as a group

This study revealed that 1.3 million Australian women who participate in netball enjoy:

- social benefits because the participants become friends

- career benefits because they know how to work together in a team

- sleep better because their stress levels are lower, compared to women who do not participate in netball

Two hundred netball players between the ages of 18 and 39 and a control group of 253 nonplayers were included in the sample.

From the discussion it is obvious that participation in netball should enhance the acceptance of and cooperation between team members from diverse backgrounds. 


\section{Research Design}

\section{Research Approach}

In the exploratory study reported on in this article, a qualitative approach was applied. Qualitative methods are used to give a meaning to and interpret people's experience. This is difficult to achieve if the researcher uses only quantitative methods (Rice \& Ezzy 2002:4). A qualitative design, however, encourages the discovery of new insights and ideas and requires a flexible approach. The approach followed in this research and presented in this article entails the interpretive paradigm, because it was necessary for the researcher to understand the way in which the participants interpreted their experiences of participation in organisational team sport activities and the benefits they perceived this to have for organisations.

\section{Research Procedure}

Two financial organisations participated in the study. The researcher has played a team sport (action netball) for more than eight years and thus has personal experience of the importance of organisational team sport for an organisation. She was also known to some of the participants working in the financial organisations, and this helped to establish a good working relationship between the researcher and the participants. Follow-up interviews were conducted with participants who were present at the focus group interviews, but who did not participate actively. This was done to ensure that they agreed with the responses obtained from the groups. The researcher felt the need to interview two black female participants separately to expand the diversity in the sample group. Data saturation occurred during the focus group interviews, and further data gathering was therefore not considered necessary.

\section{Population}

The research population for this study comprised all employees from the two identified financial institutions in Pretoria who were members of an organisation action netball team. A convenience sample was used because the participants were readily available.

\section{Sample}

A non-probability purposive sampling technique was used to identify 26 participants for the focus group interviews and individual interviews. To be included in the purposive sample, the participants had to meet both of the following criteria: they had to participate in an organisation action netball team; and they had to be permanently employed at one of the two financial institutions.

\section{Data Collection}

Tesch (1990:56) points out that qualitative research can be conducted exclusively through words, because words are used in language and language is used for communication. Words are used to interpret the information. In this study, verbatim data from the focus group interviews and follow-up interviews were collected. A time was set and the interviews, of approx- 
imately one hour's duration, were conducted in a boardroom at the participants' workplace, as this would ensure that there were no interruptions.

Guided interviews were used in the study. This balanced type of interview was used in order to allow the researcher to attain the preset goals. The use of guiding and open-ended questions simultaneously afforded the participants the opportunity to express themselves freely (Hein 1980:29). The researcher also compiled field notes that contained facts about the interviews, the interview setting and her personal observations and impressions.

This qualitative research project relied on the researcher for data gathering and analysis. The possibility of bias was overcome through peer review. An experienced researcher reviewed the interviews, transcriptions, analysis and coding and a colleague (an industrial psychologist) accompanied the researcher to all the interviews and took handwritten notes. This enabled the researcher to listen attentively to the participants and ask the necessary probing questions where applicable, while the industrial psychologist took down notes.

\section{Limitations of the Study}

Since the study was conducted at two financial organisations, the findings cannot be generalised. When considering transferability of the findings, the context in which the study was conducted should be taken into account. It is recommended that the research be repeated to include more differentiation of organisations and a larger sample group.

The researcher interviewed only those participants who were members of an action netball team. Several other sports such as hockey, cricket, soccer, rugby and volleyball should also be considered as team sports.

\section{Data Analysis}

The focus group interviews were audio-taped and transcribed verbatim. The audio-taped interviews were typed in one-and-a-half spacing with wide margins to enable the researcher to make written comments. Recurring themes and important concepts were gained from the transcript. The data-gathering process proposed by Tesch (1990:56) was used. This entailed categorising the identified themes into a smaller number of broader groups. The completed transcript was reviewed to identify any themes or concepts that had not initially been noted. The participants remained anonymous.

\section{Ethical Consideration}

Focus interviews were conducted in a venue that ensured the comfort and privacy of the participants. For this a private boardroom was used where no or limited disturbances occurred. Another ethical consideration entailed ensuring that the participants' written, informed consent was obtained prior to their participation in the study (Silverman 2002:201).

\section{Characteristics of the Sample}

Of the participants in the research reported on in this article, $65,4 \%$ were female and $34,6 \%$ were male. Almost half the participants $(46,2 \%)$ were between the ages of 20 and 25 , and $15,4 \%$ between the ages of 26 and $30.11,5 \%$ of the participants were between the ages of 
31 and $35 ; 15,4 \%$ were between the ages of 36 and 40 ; and 11,5\% were between the ages of 41 and 45 . Most of the participants $(69,23 \%)$ were Afrikaans speaking. Of the remainder, $11,54 \%$ were English speaking and 15,39\% spoke other African languages. The majority of the participants were Christian $(92,30 \%) ; 3,85 \%$ were Hindu and 3,85\% Bahai. Half of the participants were married; $46,15 \%$ were single and $3,85 \%$ were engaged to be married. The participants were from different occupational levels and worked in different departments.

\section{Findings and Discussion}

\section{Theme 1: Experience of Diversity}

\begin{tabular}{|l|l|}
\hline Sub-theme 1.1: Advantages of diversity in the workplace \\
\hline Question: What are the advantages of working in a diverse environment? \\
\hline Results & Confirmation \\
\hline Productivity & $\begin{array}{l}\text { Participant 3: "with everyone's differences and how they grew up, if they } \\
\text { put it together you can make a strong organisation which could help the } \\
\text { organisation in productivity." } \\
\text { Participant 5: "it is important to respect a person's different ways of doing } \\
\text { things but you can't allow complete freedom. You almost need to try and } \\
\text { bring it in and maybe everybody needs to sort of like adapts slightly so that } \\
\text { you can be more productive. You do want diversity at work". } \\
\text { Participant 7: "diversity helps our company to be more productive." } \\
\text { Participant 12: "but if you manage diversity correctly, then it definitely can } \\
\text { increase productivity, because you have different people doing things dif- } \\
\text { ferently and that give the company the ability to do more in less time." } \\
\text { Participant 23: "Different people view things differently and different cul- } \\
\text { tures think differently and when the organisation takes all the different } \\
\text { views into consideration it will definitely give them an advantage above } \\
\text { the other organisations." }\end{array}$ \\
\hline $\begin{array}{l}\text { Creativity and } \\
\text { innovation }\end{array}$ & $\begin{array}{l}\text { Participant 6: "Definitively also creativity and innovation. A person coming } \\
\text { from Kwazulu-Natal will have different opinions and different ways of } \\
\text { doing certain things. So innovation is also an advantage for diverse organ- } \\
\text { isations." } \\
\text { Participant 25: "It is true that the differences in an organisation can help } \\
\text { an organisation to grow. Some people think it this way and other people } \\
\text { think it that way and somewhere you find a common point". }\end{array}$ \\
\hline $\begin{array}{l}\text { Interesting } \\
\text { environment } \\
\text { new things }\end{array}$ & $\begin{array}{l}\text { Participant 1: "It makes the environment interesting. You learn from one } \\
\text { another." } \\
\text { Participant 21: "It makes an organisation interesting. Everyone is different." }\end{array}$ \\
$\begin{array}{l}\text { Participant 24: "Diversity opens up your mind and experience to other } \\
\text { things you were not exposed to." }\end{array}$ \\
\hline
\end{tabular}


The researcher asked whether the participants thought that diversity could improve productivity, and to substantiate their answers. The participants agreed that if diversity is not managed, it is impossible for the organisation to grow. Organisations need to manage their diversity because different employees do things differently, and that enables the organisations to do more in less time.

The participants were aware of the advantages that diverse organisations can offer. However, diversity needs to be properly managed. If an organisation is able to manage its diversity, it will have an advantage over its competitors.

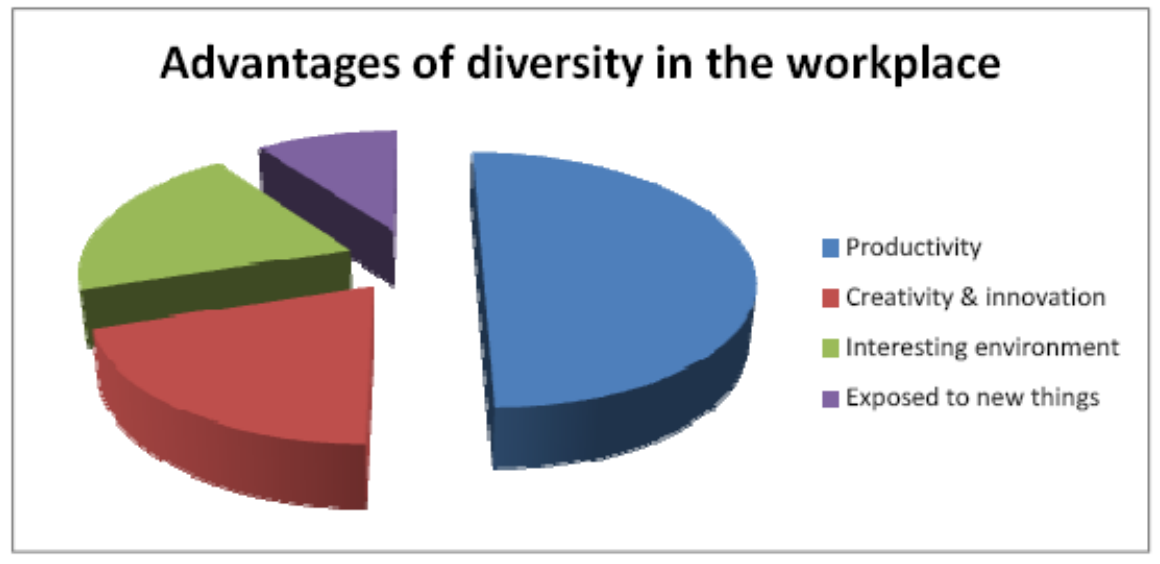

Figure 2: Advantages of Diversity in the Workplace

\begin{tabular}{|l|l|}
\hline Sub-theme 1.2: Diversity constraints in the workplace \\
\hline Question: What are the disadvantages of working in a diverse environment? \\
\hline Results & Confirmation \\
\hline Language & $\begin{array}{l}\text { Participant 16: "My biggest constraint would be language. It is difficult for } \\
\text { me to express myself in English." } \\
\text { Participant 17: "Language can be a barrier because we are used to shouting } \\
\text { in Afrikaans on the court but half the time I sometimes forgets that some } \\
\text { of the participants are English." } \\
\text { Participant 18: "Language, it is difficult to communicate with each other } \\
\text { if you don't speak the same language." } \\
\text { Participant 26: "Language can be a barrier because someone can say } \\
\text { something and the other person takes it in the wrong context clearly because } \\
\text { they don't know what you mean by it." }\end{array}$ \\
\hline Culture & $\begin{array}{l}\text { Participant 20: "Culture or race can also be a problem. We don't always } \\
\text { understand the other culture's backgrounds and believes." } \\
\text { Participant 25: "A lot of people say something that has a different meaning } \\
\text { in another culture." }\end{array}$ \\
\hline Gender & $\begin{array}{l}\text { Participant 21: "Gender is also a problem. Men think differently than } \\
\text { women." }\end{array}$ \\
\hline
\end{tabular}




\begin{tabular}{|l|l|}
\hline Generations/ & $\begin{array}{l}\text { Participant 6: "The other day some of my colleagues had a meeting and he } \\
\text { said that they were all born in the late 60's and they are all Baby Boomers } \\
\text { and I am from Generation Y. I think we have to look at that, to help the } \\
\text { company to go forward because top management is all before the Baby } \\
\text { Boomer time and the rest of the organisation is more from the } \\
1970 \text { 's/1980's." } \\
\text { Participant 17: "Age can also be a problem. Young people don't want to } \\
\text { have conversations with old people." } \\
\text { Participant 20: "Because I am almost the eldest, I think age can also be a } \\
\text { constraint." }\end{array}$ \\
\hline
\end{tabular}

The researcher asked whether diversity is bad. The participants responded that although diversity makes the organisation interesting, everyone is different. People need to work together in a team, and diversity opens up one's mind and experiences to other things one was not otherwise exposed to.

The participants' perceptions support the view of Nieman and Bennett (2002:332) that effective communication is an important requirement for effective diversity management in the workplace. Daiana (n.d.:1) states that employees need to understand the various different cultures, and this is another vital requirement for effective diversity management in the workplace. Aker (2009:46) expresses the view that employees need to understand the different generations.

\section{Diversity constraints in the workplace}

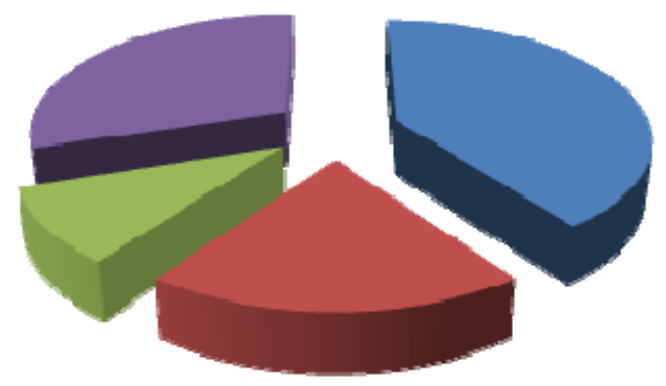

Figure 3: Diversity Constraints in the Workplace

Theme 2: Experiences when Participating in Organisational Team Sport with Diverse Co-workers 


\begin{tabular}{|c|c|}
\hline \multicolumn{2}{|c|}{$\begin{array}{l}\text { Sub-theme 2.1: Organisational team sport outcomes that reduce diversity constraints } \\
\text { and advance the achievement of diversity management objectives }\end{array}$} \\
\hline \multicolumn{2}{|c|}{ Question: What are the advantages of participating in a diverse sports team? } \\
\hline Results & Confirmation \\
\hline Trust and respect & $\begin{array}{l}\text { Participant 19: "We also ensure that we are on time for the games. The } \\
\text { team needs us and we need them. We trust and respect one another." } \\
\text { Participant } 24: \text { "You learn more about each other and when you under- } \\
\text { stand a person and you know a person or when you are willing to go } \\
\text { the extra mile, things immediately will become better, the trust issue } \\
\text { and the respect issue." } \\
\text { Participant } 25: \text { "We are very close knit. We depend on each other in } \\
\text { the team. Trust is very big in our team." }\end{array}$ \\
\hline Support & $\begin{array}{l}\text { Participant 12: "We do get more support from one another if you play } \\
\text { together in a team." }\end{array}$ \\
\hline $\begin{array}{l}\text { Open } \\
\text { communication }\end{array}$ & $\begin{array}{l}\text { Participant 12: "Sport definitely enables a more open communication } \\
\text { than we had before the time. When we played the departmental games, } \\
\text { it made a big difference to communication. You can work with a person } \\
\text { who sits next to you for } 5 \text { years and never really speak to him if you } \\
\text { don't do anything outside work together." } \\
\text { Participant 17: "Because we play in the same team, we don't just walk } \\
\text { past them what we would have done if we have not played in the same } \\
\text { team. We actually stop and start a conversation." }\end{array}$ \\
\hline $\begin{array}{l}\text { Relationships/ } \\
\text { Friends }\end{array}$ & $\begin{array}{l}\text { Participant } 14 \text { : "the people were on higher levels than me, so you greet } \\
\text { one another, but that is all, but when you play sport together, everyone } \\
\text { was almost like on equal level, I mean, we had more of an upper hand, } \\
\text { because we knew the game and some of them didn't and the 'fights' } \\
\text { that broke out were incredible. Everyone wants to play the same posi- } \\
\text { tions. And yes, the whole office was more friendly with one another } \\
\text { after that." } \\
\text { Participant 15: "Sport makes friends that would normally not happen." } \\
\text { Participant 17: "Well, I wouldn't know them that well if they didn't } \\
\text { play netball. One of the other netball players that is playing in another } \\
\text { team is working in the finance department and if I need something } \\
\text { from the finance department, I normally phone him because, regardless } \\
\text { of the fact that he knows everything, he became my friend." }\end{array}$ \\
\hline
\end{tabular}




\begin{tabular}{|l|l|}
\hline $\begin{array}{l}\text { Learn about each } \\
\text { other }\end{array}$ & $\begin{array}{l}\text { Participant 14: "We learn more about the other culture's background." } \\
\text { Participant 15: "Before the departmental challenge, you would walk } \\
\text { past someone and didn't greet them at all, but after the departmental } \\
\text { challenge where you were talking and joking with one another, the } \\
\text { next day at work you can actually greet him and have a chat." } \\
\text { Participant 22: "We had an interdepartmental challenge last week where } \\
\text { we played action soccer, action netball, action cricket and volleyball } \\
\text { and some co-workers in our department were so good in sport, we } \\
\text { never even knew that until we had this inter departmental challenge." } \\
\text { Participant 25: "I learnt a lot from the other people [in the team]." }\end{array}$ \\
\hline Commitment & $\begin{array}{l}\text { Participant 14: "We practise during the week, after work. Even though } \\
\text { we do it for fun, there is still commitment." } \\
\text { Participant 19: "We also ensure that we are on time for the games and } \\
\text { if we practise, we make sure that we are there, because the team needs } \\
\text { us and we need them." }\end{array}$ \\
\hline Less absenteeism & $\begin{array}{l}\text { Participant 12: "Employees are less sick. If you can bring down your } \\
\text { absenteeism by 5\% you save millions a year. If you sponsor people } \\
\text { to stay fit, the company will definitely benefit." }\end{array}$ \\
\hline
\end{tabular}

Participants were also asked whether they knew the netball players belonging to the other teams at that specific organisation. They reported that they knew them and that when the other teams were playing, they would sit beside the court and support them. They also became friends with the participants in the other teams, and when the other teams needed a team player, they would be more than willing to help out. According to one participant, the whole team supported other teams such as those playing rugby, soccer, cricket and volleyball, and not just the netball teams.

The participants' perceptions bear out the advantages listed in figure 1, confirming that employees who share knowledge, time and space usually become friends. This also confirms the views of Cashmore (2003:66) that participation in organisational team sport improves individual commitment. Kortex (2006:1) holds that participation in organisational team sport improves mutual trust among employees. Downs (2009:1) contends that participation in organisational team sport improves mutual respect between employees. Carrigg (2007:1) is of the opinion that organisational team sport participation improves inter-employee communication, while Muleskinner (2003:1) confirms that participation in organisation team sport enhances employees' interpersonal knowledge of other employees. 


\section{Experiences when participating in organisational team sport with diversity co-workers}

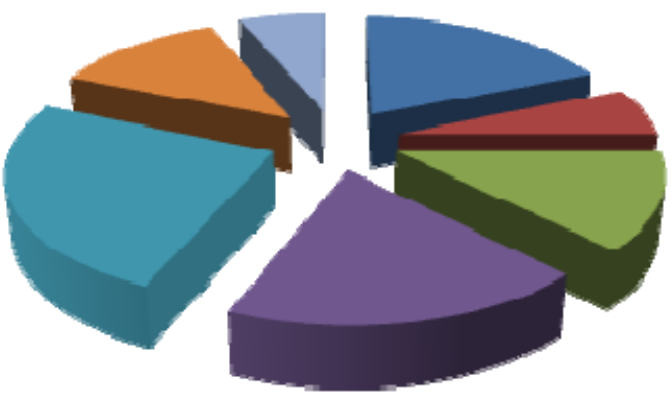

- Trust \& respect

- Support

ncommunication

ariends

nearn about each other

commitment

ness absenteeism

Figure 4: Experiences when Participating in Organisational Team Sport with Diverse Coworkers

\begin{tabular}{|l|l|}
\hline Sub-theme 2.2: & Benefits of sport events in organisations \\
\hline $\begin{array}{l}\text { Question: Do you think that organisations need to use sport to minimise diversity } \\
\text { constraints in the organisation? }\end{array}$ \\
\hline Results & Confirmation \\
\hline $\begin{array}{l}\text { Trust and re- } \\
\text { spect }\end{array}$ & $\begin{array}{l}\text { Participant 10: "I feel trusted in the netball team as well as in the soccer } \\
\text { team.” } \\
\text { Participant 26: "you learn from one another, there are trust and respect } \\
\text { and friendship between the participants." }\end{array}$ \\
\hline Support & $\begin{array}{l}\text { Participant 10: "To go back to the support, even though we don't work } \\
\text { together, if we walk past one another and see that he is down, and he says } \\
\text { that it is not going so well, you do support him." }\end{array}$ \\
\hline $\begin{array}{l}\text { Relationships/ } \\
\text { Friends }\end{array}$ & $\begin{array}{l}\text { Participant 25: "and friendship." } \\
\text { Participant 26: "me and the girl are now friends and from 1 January I will } \\
\text { start to work with her in the same department, so I already have a friend } \\
\text { by the time I move in there, so it is quite nice." }\end{array}$ \\
\hline Communication & $\begin{array}{l}\text { Participant 25: "it is easier for me to go to one of them since I know them } \\
\text { in a way instead of going to someone I never had to deal with in the com- } \\
\text { pany before." } \\
\text { Participant 26: " because I know her, I can talk to her about other stuff } \\
\text { and not only work, because she knows me on a more personal level." }\end{array}$ \\
\hline
\end{tabular}




\begin{tabular}{|l|l|}
\hline $\begin{array}{l}\text { Learn more } \\
\text { about each other }\end{array}$ & $\begin{array}{l}\text { Participant 10: “and I play soccer with the guys as well, and I mean, I am } \\
\text { the only 'whitey' and I would not have gotten to know them as well as I } \\
\text { do today, had I not been playing with them in a team.” } \\
\text { Participant 25: "in terms of sport in companies, especially big companies, } \\
\text { there are so many people and you are so busy during the day that you } \\
\text { never get the time to know the people you are working with, so things like } \\
\text { sport and team outings help a lot, not only in growing yourself, but in } \\
\text { knowing your fellow players but also the people who are working with } \\
\text { you." } \\
\text { Participant 26: "And also when you play with other people in a team you } \\
\text { also get to know that person's good behaviour and bad behaviour. You } \\
\text { know when they are upset about something and when they are excited. You } \\
\text { get to know both sides of the coin instead of just sitting together in an of- } \\
\text { fice." }\end{array}$ \\
\hline
\end{tabular}

The participants were asked whether they thought that sport was time-consuming and whether the company would lose productivity because of the time spent on sport events. At the time of the interviews, the participants were all playing in an action netball team and all their games took place after hours. The participants agreed that when organisational team sport is implemented in organisations the participants feel valued. They are willing to work longer hours and to work towards company success because they are now friends. Sport also increases open communication, support and commitment among employees. The organisations do not lose production time. The converse is actually true: the company gains more from employees who participate in sport.

The participants' perceptions once again support the view regarding the advantages listed in figure 1, which confirms that employees who share knowledge, time and space usually become friends. Their perceptions also confirm the view of Cashmore (2003:66) that participation in organisational team sport improves individual commitment. Kortex (2006:1) holds that participation in organisational team sport improves mutual trust among employees. Downs (2009:1) contends that participation in organisational team sport improves mutual respect between employees. Carrigg (2007:1) is of the opinion that participation in organisational team sport improves inter-employee communication, while Muleskinner (2003:1) confirms that participation in organisation team sport enhances employees' interpersonal knowledge of other employees. 


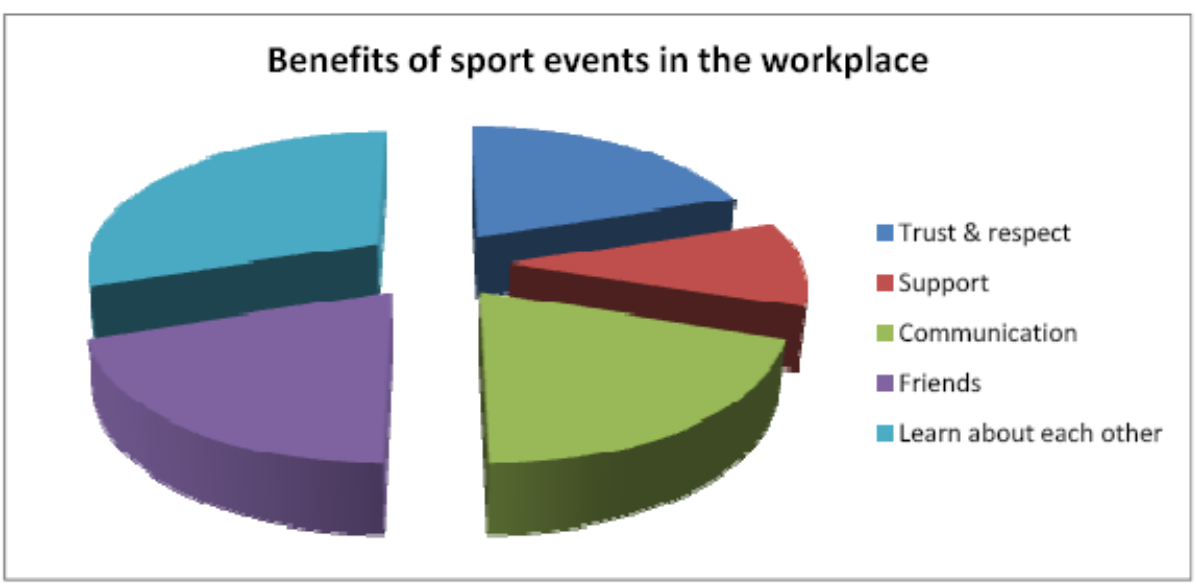

Figure 5: Benefits of Sport Events in the Workplace

\begin{tabular}{|l|l|}
\hline \multicolumn{2}{|l|}{ Sub-theme 2.3: Advantages of being able to engage in conversations about sport } \\
\hline Question: Do you talk about sport in the workplace? \\
\hline Results & Confirmation \\
\hline $\begin{array}{l}\text { Breaks down } \\
\text { barriers }\end{array}$ & $\begin{array}{l}\text { Participant 12: "when you talk about sport, it always breaks that initial } \\
\text { barrier." }\end{array}$ \\
\hline $\begin{array}{l}\text { Common } \\
\text { ground }\end{array}$ & $\begin{array}{l}\text { Participant 12: "when you talk about sport it is a common ground and } \\
\text { usually sport falls nicely into that." }\end{array}$ \\
\hline People connect & Participant 19: "It is nice to talk about sport, sport makes people connect." \\
\hline Ice breaker & Participant 20: "just to break the ice." \\
\hline
\end{tabular}

The participants' views are supported by Bernstein, Alexander \& Alexander (2008:22), who confirm that a multigenerational and diverse workplace can be effectively managed when individuals are willing to find a common ground. Johnson (2008:1) confirms this statement by adding that sport is a perfect icebreaker in many organisations, especially when diverse teams have no other common ground. 


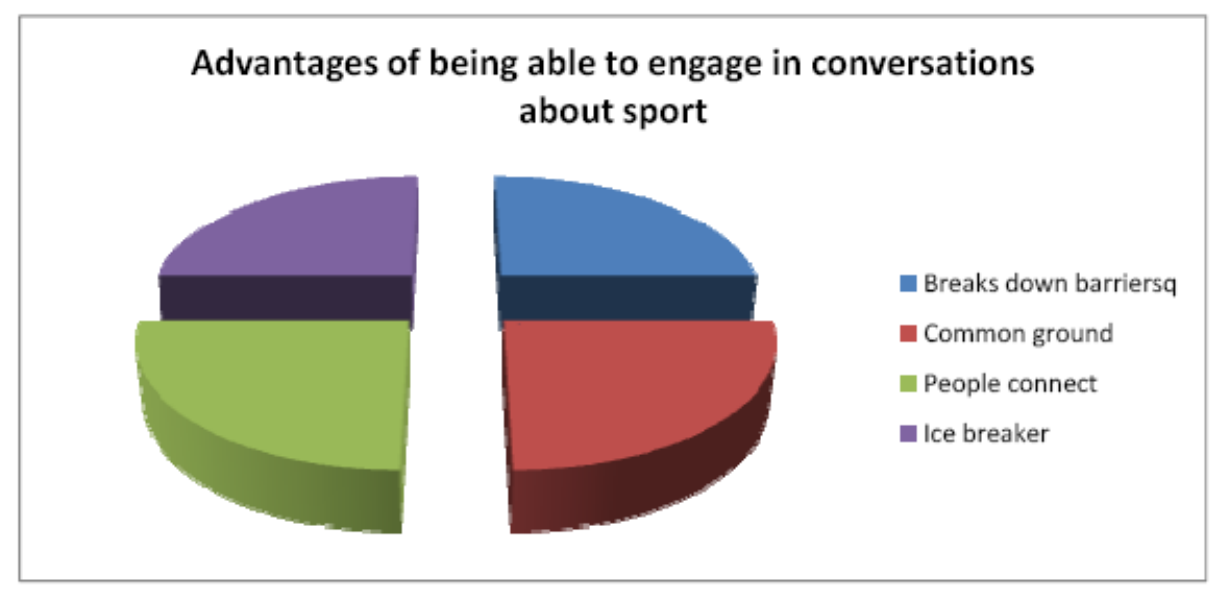

Figure 6: Advantages of Being Able to Engage in Conversations about Sport

\section{Conclusion}

The main aim of the study was to determine whether participation in a formal organisational team sport intervention affects the diversity constraints between employees employed at a financial organisation. The sample was represented by diverse employees working at two financial organisations that permit participation in action netball.

The contribution that organisational team sport makes to the effective management of diversity takes the form of a strong bond established among employees in the organisation during sport events. Business relationships can be created while talking about sport, attending sport events or playing sport. Organisational team sport is therefore a means for creating opportunities to share goals, improve commitment, increase trust and respect, improve communication among employees and enhance employees' knowledge of other employees. The contributions that organisational team sport makes to an organisation are all requirements for effective diversity management in the workplace.

It is therefore recommended that organisational team sport be used in diverse organisations to minimise diversity constraints.

\section{References}

Aker, J.M. (2009). Managing a multigenerational workforce. Buildings, 103(1), January: 46.

Bassett-Jones, N. (2005). The paradox of diversity management, creativity and innovation. Creativity and Innovation Management, 14(2): 169-175.

Bernstein, L., Alexander, D. \& Alexander, B. (2008). Generations: harnessing the potential of the multigenerational workforce. The Catalyst, 37(3), Winter: 17.

Carrigg, C. (2007). Sports helps with diversity. Available from www.the-kingdom.ie. (Accessed 23 December 2008).

Cashmore, E. (2003). Sport psychology: the key concepts. 2nd edition. London \& New York: Routledge Taylor \& Francis.

Daiana, C. (n.d.). The importance of understanding cultural differences in business. Available from www.helium.com. (Accessed 21 October 2009). 
THE INTERNATIONAL JOURNAL OF DIVERSITY IN ORGANISATIONS, COMMUNITIES AND NATIONS

Downs, C. (2009). Kids learn Bible lessons on respect via sport. Available from http://biblestudies.suite101.com. (Accessed 12 February 2010).

E-News. (2009). News Late Edition, 23 September.

Hein, E. (1980). Communication in nursing practice. Boston: Little Brown.

Hewett, S. (2001). Playing for success: Netball "breeds leaders". Sunday Telegraph, Sydney, 13 May: 34.

Johnson, T. (2008). Sports in the office: how to make sure you have your bases covered. Available from www.experience.com. (Accessed 23 December 2008).

Kortex, J. (2006). Unity in sports. Available from www.articlecity.com. (Accessed 12 February 2009).

Lapchick, R.E. (2005). Sport as a bridge across the racial divide. Available from http://digitalcommons.unl.edu. (Accessed 10 July 2009).

Muleskinner, K.M. (2003). Sports a bridge for racial diversity. College Media Network. June. Available from http://media.www.themuleskinner.com. (Accessed 23 December 2008).

Nieman, G. \& Bennett, A. (2002). Business management: a value chain approach. Pretoria: Van Schaik.

Rice, P.L. \& Ezzy, D. (2002). Qualitative research methods: health focus. Oxford: Oxford University Press.

Sawer, P. (2007). Sport “good for business". Evening Standard, 7 May: 33.

Silverman, D. (2002). Doing qualitative research: a practical handbook. London: Sage.

Solomon, M.S. (1998). Building teams across borders. Workforce, 3(6), November.

Tesch, K. (1990). Qualitative research: analysis, types and software tools. New York: Falmer Press.

\section{About the Authors}

Yvonne Joubert

University of South Africa, South Africa

Prof. Hannes de Beer

University of Pretoria, South Africa 


\section{EDITORS}

Mary Kalantzis, University of Illinois, Urbana-Champaign, USA.

Paul James, Globalism Institute, RMIT University, Australia

\section{EDITORIAL ADVISORY BOARD}

Ien Ang, University of Western Sydney, Sydney, Australia.

Joanna van Antwerpen, Research and Statistics, Amsterdam, The Netherlands.

Samuel Aroni, University of California, Los Angeles, USA.

Susan Bridges, University of Hong Kong, Hong Kong.

Duane Champagne, University of California, Los Angeles, USA.

Guosheng Y. Chen, RMIT University, Melbourne, Australia.

Jock Collins, University of Technology, Sydney, Australia.

Bill Cope, University of Illinois, Urbana-Champaign, USA.

Heather Marion D'Cruz, Deakin University, Geelong, Australia.

James Early, Smithsonian Institution, Washington, D.C., USA.

Denise Egéa-Kuehne, Louisiana State University, Baton Rouge, USA.

Amareswar Galla, University of Queensland, Brisbane, Australia.

Grethe van Geffen, Seba Cultuurmanagement, Amsterdam, The Netherlands.

Barry Gills, Newcastle University, Newcastle upon Tyne, UK.

Jackie Huggins, University of Queensland, Brisbane, Australia.

Andrew Jakubowicz, University of Technology, Sydney, Australia.

Paul James, Globalism Institute, RMIT University, Melbourne, Australia.

Ha Jingxiong, Central University of Nationalities, Beijing, China.

Mary Kalantzis, University of Illinois, Urbana-Champaign, USA.

Jack Levin, Northeastern University, Boston, USA.

Cristina Poyatos Matas, Griffith University, Brisbane, Australia.

Peter McLaren, University of California, Los Angeles, USA.

Joe Melcher, Xavier University of Louisiana, New Orleans, USA.

Greg Meyjes, Solidaris Intercultural Services, Falls Church, USA.

Walter Mignolo, Duke University, Durham, USA.

Brendan O'Leary, University of Pennsylvania, Philadelphia, USA.

Aihwa Ong, University of California, Berkeley, USA.

Peter Phipps, Globalism Institute, RMIT University, Melbourne, Australia.

Ronald Prins, Bos en Lommer Neighbourhood Council, Amsterdam-West, The Netherlands.

Peter Sellars, University of California, Los Angeles, USA.

Michael Shapiro, University of Hawai'i, Manoa, USA.

David S. Silverman, Kansas Wesleyan University, Salina, USA.

Martijn F.E. Stegge, Diversity Platform, Amsterdam, The Netherlands.

Geoff Stokes, Institute for Citizenship and Globalisation, Deakin University, Melbourne, Australia.

Terry Threadgold, Cardiff University, Wales, UK.

Mililani Trask, Permanent Forum on Indigenous Issues for the Economic Council of the UN Assembly, Hawai'i, USA.

Marij Urlings, Inholland University, Amsterdam-Diemen, The Netherlands.

Rob Walker, Keele University, Keele, UK.

Ning Wang, Tsinghua University, Beijing, China.

Owens Wiwa, African Environmental and Human Development Agency, Toronto, Canada. 